\title{
Simulating the life course of psoriasis patients: The interplay between therapy intervention and marital status
}

\author{
Dennis Linder ${ }^{1 \S}$, Arnoldo Frigessi ${ }^{1}$, Stefano Piaserico ${ }^{2}$, Nico Keilman $^{3}$ \\ ${ }^{1}$ Oslo Centre for Biostatistics and Epidemiology, University of Oslo, Oslo, Norway \\ ${ }^{2}$ Dermatology Unit, Department of Medicine, Padua University, Padua, Italy \\ ${ }^{3}$ Department of Economics, University of Oslo, Oslo, Norway \\ §corresponding author: \\ Michael Dennis Linder, MD: Oslo Centre for Biostatistics and Epidemiology, University of Oslo, \\ P.O.Box 1122 Blindern - 0317 Oslo. Email: michael.dennis.linder@gmail.com
}

\begin{abstract}
Background: psoriasis, a chronic relapsing inflammatory disease affecting primarily the skin, shows multiple comorbidities including depression, cardiovascular diseases and other relevant conditions. Psoriasis patients experience social isolation, job loss, financial difficulties, and partnership problems. Inversely, psychosocial impairments may negatively influence the disease course.

Objective: To explore the feasibility of a model describing the interaction of psychosocial and clinical factors over the life course of patients.

Methods: we considered only seven states for members of a hypothetical population: single and healthy, single and having a psoriasis flare, single and "cured", coupled and healthy, coupled and having a psoriasis flare, coupled and "cured", and dead. Transition probabilities between states were taken from the Norwegian Population Register for the healthy population and from epidemiological research articles. Clinical experience allowed adjustments on the assumed parameters.

Results: Our macro-model, which simulates the effect of therapy intervention on patients' partnership status, yields a description of the transitions between the seven states. Treatment efficacy shows only a negligible effect on the chances of living with a partner.

Conclusions: Mathematical modelling of interactions between social and health variables is in principle feasible. However complex models, comprising more variables (for instance: employment status, depression level, obesity etc.) are needed for more realistic simulations for the interactions studied. Since increasing the number of variables leads to an exponential increase of the model's state space, switching to micro-modelling (representing each individual separately) may be necessary.
\end{abstract}

Keywords: $\quad$ psoriasis, life course research, mathematical modelling, biopsychosocial, cumulative life course impairment (CLCI)

Key message: A computer simulation explores the interaction between a social and a health variable for psoriasis.

Running head: Life course simulation in psoriasis

This article has been accepted for publication and undergone full peer review but has not been through the copyediting, typesetting, pagination and proofreading process, which may lead to differences between this version and the Version of Record. Please cite this article as doi: $10.1111 /$ jdv. 14567

This article is protected by copyright. All rights reserved. 


\section{Introduction}

Psoriasis presents as the ideal candidate for the so-called Life Course Approach [1]: the interplay of the various comorbidities and different forms of psychosocial impairment presenting with this disease [2-7] are likely to inflict a permanent "damage" to the life course - cumulative life course impairment (CLCI) [7]: patients are in danger of living a life "not up to their full potential".

Gaining insight into the interactions between psychosocial and biological variables of a chronic disease represents a challenge ${ }^{1}$. For psoriasis, validated life course questionnaires [10], which might deliver useful data, have not been developed to date. Moreover, since relevant information of this kind can only be collected retrospectively, all questionnaire-based results are likely to suffer from recall bias. A model-based approach, i.e. a mathematical model simulating the life courses of patients over an extended period of time, may provide an innovative way to meet the above challenge. Indeed, in spite of the plethora of publications dedicated to psoriasis and its biopsychosocial comorbidities, mostly based on cross-sectional studies, no mathematical models have been set up so far that simulate the consequences of the various comorbidities over the life course of the patient, the interactions of these comorbidities, and the possible benefits of early therapeutic interventions.

Once constructed, models of life course trajectories as influenced by psoriasis and its accompanying physical, psychological and social ailments will serve several purposes, such as:

- simulate the effects of treatment on the life trajectory of individuals to ascertain how these effects depend on the time of intervention, duration of intervention etc.

- allow estimation of "cumulative exposure times" in damaging states, a promising feature, since it is reasonable to assume that exposure to "wear and tear" over time (so called "allostatic load") is likely to cause permanent damage to the organism; for example, a patient with severe psoriasis has a higher risk than the average healthy person for arterial hypertension; the longer the patient is exposed to the state "high arterial pressure", the higher the risk for cardiovascular events.

Modelling and simulation of life trajectories [11] can happen on a macro, micro or micro-macro level. Macro-models simulate the life course of a group of individuals. Micro-models take the individual person as the unit of analysis, and include interactions between individuals, for instance in the case of marriage. In combined micro-macro models one simulates individual life courses as in pure micromodels, but one also takes account of variables at the macro level, such, for instance, as the number of available marriage partners. Compared to a micro-model, a macro-model produces less detailed results, as it simulates the life course of a group of persons only, thereby losing individual detail.

The aim of the current study is to simulate in a macro-model the life course of a cohort of persons aged 10-14, who are subject to odds of acquiring psoriasis, experiencing relapses of the illness, entering marriage/cohabiting partnership, and marriage/partnership dissolution.

\footnotetext{
${ }^{1}$ A first important insight into the mechanism prompting psoriasis patients to suffer this "damage of their life trajectories" is given in [8], where a mathematical model of the Matthew Effect in Life Course Analysis is discussed. The term "Matthew Effect", which describes the fact that " intra-cohort inequality is magnified over a life course because people accumulate different amounts of advantages and disadvantages over time" is derived from the Gospel of Matthew, in which Jesus says, "For unto every one that hath shall be given, and he shall have abundance: but from him that hath not shall be taken away even that which he hath." (Matthew 25:29) [9].
}

This article is protected by copyright. All rights reserved. 
In particular, by making use of assumptions - based on clinical experience and on the data available in literature -

(a) on the effect exerted by living with or without a partner on the effectiveness of treatment

and

(b) on the effect exerted by being affected by manifest psoriasis on the chances of finding a partner (respectively becoming separated from a partner).

we aim, by running the model, to make, for patients, predictions on

c) the total time over a life course when the disease is in remission

and

d) the total time spent in a relationship over a life course.

By varying the assumption on the effectiveness of treatment to prevent relapses, such a model will therefore allow to predict how the life course changes as a result of treatments with different effectiveness. In our simplified model, we can aim to assess how a "better" treatment can lead to a "different" life (i.e. more lifetime spent with a partner.)

Note that the model does not provide directly clinical information: it provides information on the effect of both the disease and of its treatment on the life course of patients ${ }^{2}$.

\section{Model}

At any age $\mathrm{x}$, a person can be in one of two marital/cohabitational states: living in a couple - that is, either with a marriage partner or a cohabitee - (COUPLED), or living without a partner (SINGLE). In addition, we distinguish between three states for the disease: belonging to the source population - in other words, being healthy - (HEALTHY), with psoriasis (PSO), and "cured"- that is having had psoriasis but under remission - (CURED). Under CURED we do not, for the purpose of this study, indicate only patients who are completely cleared of their psoriasis, but rather also patients with - at most - mild psoriasis. As usual, mild disease is defined as body surface area (BSA) $\leqslant 10$ and psoriasis area and severity index (PASI) $\leqslant 10$ and dermatology life quality index (DLQI) $\leqslant 10$ and moderate to severe psoriasis as $(\mathrm{BSA}>10$ or $\mathrm{PASI}>10)$ and $\mathrm{DLQI}>10$.

By combining the three disease states and the two marital states we define the state space of the model, which consists of the following six states:
HEALTHY - SINGLE
not (yet) affected by psoriasis, single
PSO- SINGLE
with active psoriasis, single
CURED - SINGLE
affected by psoriasis, now in remission, single

\footnotetext{
${ }^{2}$ Still, sensitivity analysis (SA) [12] may, in a second step, allow drawing conclusions on the chosen parameters. In SA one investigates how different values of an independent variable impact a particular dependent variable under a given set of assumptions; in our case, SA may allow for instance to draw conclusions on the degree of effectiveness of the treatment: assume that running the model under a certain assumption of degree of effectiveness $E$ of the treatment may lead to a certain $\mathrm{R}$ rate of cured patients resulting in a prevalence of patients with active disease that turns out to be higher than the epidemiologically assessed prevalence, say R', $<$ R. Then this would allow us to conclude that the " real" effectiveness of the treatment is actually, say E', $<$ E.
} 
HEALTHY - COUPLED
PSO - COUPLED
CURED - COUPLED

We add the state of DEAD for completeness. Thus the state space consists of seven states.

We denote by HEASIN ${ }_{\mathrm{x}}$ the number of individuals in the population who are healthy and single at age $\mathrm{x}$, and similarly for the other five combined states.

Let us define a column vector $\mathrm{V}^{\mathrm{x}}$ to describe the population at age $\mathrm{x}$, broken down by disease status and marital status, i.e. the first component of the vector will indicate the number of individuals in the age group $\mathrm{x}$ who are healthy and single (HEASIN), the second component will indicate those who are in state PSOSIN, etc.: the $j_{\text {th }}$ component of the vector shall indicate the amount of individuals $v_{j}$ which find themselves at age $\mathrm{x}$ in the state $\mathrm{j}$. Let us further define a $7 \mathrm{x} 7$ square matrix $\mathrm{P}^{\mathrm{x}}$ containing the transition probabilities that depend on age. These probabilities are a function of rates for change of disease status, marital status and for mortality.

We assume that the life course dynamics of disease and marital status - transitions between the states, which happen between age $\mathrm{x}$ and age $\mathrm{x}+1-$ can be described $^{3}$ by means of the following equation ${ }^{4}$ :

$$
\mathrm{V}^{\mathrm{x}+1}=\mathrm{P}^{\mathrm{x}} \cdot \mathrm{V}^{\mathrm{x}},
$$

The unit age interval $(\mathrm{x}, \mathrm{x}+1)$ is set to 5 years, with age groups equal to $10-14,15-19,20-24, \ldots, 75$ $79,80-84,85+$. Life courses of men and women are modelled separately.

Not all transitions between the seven states are allowed. Although people can move freely from being single to living with a partner and back, transitions between disease states are restricted: a person who has acquired the disease cannot, for instance, move back to the states HEASIN or HEACPL. Figure 1 gives the permitted transitions. Changes from one state to another one take place in infinitely short time intervals. Changes in partnership status, for instance from HEACPL to PSOSIN simultaneously with a change in disease status are therefore logically impossible, because two such events cannot take place exactly at the same time. Such changes therefore are not included in the model, which reflects immediate status changes, as mentioned above. But a person may be in state HEACPL at a certain age, and find himself in state PSOSIN five years later. This would require two events, for instance from HEACPL to HEASIN, and next from HEASIN to PSOSIN.

Loops in the graph symbolize no change of status between $\mathrm{x}$ and $\mathrm{x}+1$. Each allowed transition of individuals aged $x$ from one status $i$ to another status $j$, shown with an arrow between $i$ and $j$, happens with a certain rate $r_{j i}(x)$. The rate expresses the expected number of moves from state $i$ to state $j$ per person year of exposure in state $i$.

\footnotetext{
${ }^{3}$ By multiplying the matrix $\mathrm{P}^{\mathrm{x}}$ with the vector $\mathrm{V}^{\mathrm{x}}$, one obtains for each state $\mathrm{j}$ at age $\mathrm{x}+1$ the size of the population in state $\mathrm{j}$ : this size is namely calculated as the sum (over all states $k$ ) of the transition rates $\mathrm{p}_{\mathrm{jk}}$ (which describe the probability of moving from state $\mathrm{k}$ to state $\mathrm{j}$ ) multiplied with the number of individuals $\mathrm{v}_{\mathrm{k}}$ which are in state $\mathrm{k}$ :

$$
\mathrm{v}_{\mathrm{j}}(\text { at age } \mathrm{x}+1)=\mathrm{p}_{\mathrm{j} 1} \mathrm{v}_{1}+\mathrm{p}_{\mathrm{j} 2} \mathrm{v}_{2}+\mathrm{p}_{\mathrm{j} 3} \mathrm{v}_{3}+\mathrm{p}_{\mathrm{j} 4} \mathrm{v}_{4}+\mathrm{p}_{\mathrm{j} 5} \mathrm{v}_{5}+\mathrm{p}_{\mathrm{j} 6} \mathrm{v}_{6}+\mathrm{p}_{\mathrm{j} 7} \mathrm{v}_{7}
$$
}


The population is also assumed to be exposed to mortality (not represented graphically), with death rates that differ by state and by age. Note that the group of states \{PSOSIN, CURSIN, PSOCPL, CURCPL $\}$ is absorbing, i.e. individuals can escape this group - as a whole - of four states only through death.

To simplify the model, we have assumed that all patients with moderate to severe psoriasis are immediately treated once they present with active disease. To reflect the reality that as a matter of fact about half of patients with active moderate to severe disease are either not treated at all or not adequately treated, we have set the relapse rate higher than it can be assumed with adequate treatment (data on file). Alternatively, we would have had to define additional states.

The simulations were carried out by means of the program LIPRO ("Lifestyle projections") version 4.0. LIPRO is freely available $[13,14]$. It is based on the methodology of multi-state demography, with great flexibility to model transitions between any (reasonable) number of states. The program includes two options: it can project the life courses of a complete population (i.e. individuals of all ages) simultaneously, or it can simulate the life course of one specific age group. We used the latter option. That means that we study the life course of a hypothetical group of persons aged 10-14 years, all starting in state HEASIN. Five years later, when they are aged 15-19 years, most of them (97.2 percent) are still healthy and single 5 . Two percent are healthy but live with a partner (HEACPL), while the remaining 0.8 percent are divided equally ( 0.2 percent each) over the remaining four states PSOSIN, CURSIN, PSOCPL, and CURCPL. Then, as they age, the distribution of this cohort over the states changes continuously. At the same time mortality reduces the size of the cohort.

\section{Data and assumptions}

Data

The data on mortality and marital status changes in the general population come from the Norwegian Population Registry, as used in an earlier study [16]. They reflect the situation around the year 2000. One feature that we included in the model is the well-known fact that persons who live with a partner have lower mortality than those who live alone [17]. Transition rates between disease states, i.e. into and within the group PSOSIN, CURSIN, PSOCPL and CURCPL, are based on epidemiological data [18 -21] and on the clinical experience of two of the authors (DL, SP).

Both partnership status and disease status have an effect on the longevity of the population. Compared to non-patients, mortality of patients in remission is almost the same, but it is much larger for patients with severe psoriasis [22]. We have assumed that death rates are five percent and fifty percent higher for these two patient groups, respectively, compared to the death rates of non-patients. For a mortality age pattern such as that in Norway in current times, a fifty percent higher death rate at each age implies a life expectancy which is approximately four years lower than the life expectancy of the reference group ${ }^{6}$.

A decrease in life expectancy by only four years resulting from 50 percent higher mortality at each age may seem very little, but the intuitive explanation is that in many age groups (up to age 60, approximately) mortality is so low that any change in the death rate changes the life expectancy by a very little amount only. In developing countries, or in Norway in the past centuries, mortality at young

${ }^{5}$ We disregard, in this model, the comparatively small numbers of children with psoriasis in the age group 10-14 [15]. ${ }^{6}$ This result is based on [23], pp. 82-84, assuming that the current age pattern of mortality in Norway is characterized by an
H-value of 0.1 .

This article is protected by copyright. All rights reserved. 
ages is (was) much more important, which leads to a much stronger impact on life expectancy when death rates are increased by fifty percent.

Assumptions:

(The assumptions are crucial, as they attempt to implement in the model the interaction between a social and a biological state.)

1. Assumption: psoriasis makes union formation harder and union dissolution more frequent [24]

2. Assumption: Coupled individuals respond better to treatment (better adherence because of partners' encouragement) [25].

We have assumed that union formation rates for men and women who are affected by psoriasis but currently successfully treated (CUR) are the same as those in the "healthy" source population (HEA). For those who have a moderate to severe active disease (PSO) we have reduced the rates by one-third up to age 55. Rates for the dissolution of a union (either due to divorce, separation, or the death of the partner) are assumed 50 percent larger for those who have a moderate to severe disease, compared to the source population. In addition, we speculated even successfully treated patients to have union dissolution rates that are one third higher than the average healthy population. (To the best of our knowledge no epidemiological data are available on this respect).

Figures 2 and 3 give the age patterns of several transition rates for the source population consisting of healthy men and women, the population with psoriasis, and the persons who were previously affected. The Y-axis of Figure 3 represents a proportional scale, which means that it reflects relative differences, not absolute ones. All data represented in Fig. 2 and 3 are just input data.

Note that union dissolution for CUR has been assumed higher than union dissolution for HEA, whereas union formation for CUR is almost equal to union dissolution for to HEA. We speculated that having experienced an active disease may have but a heavy burden on a couple and hence be conducive to separation, and that successfully treated patients may lead a "normal" life and hence have similar chances of undergoing a partnership than healthy individuals.

\section{Results}

The program computed the life courses of hypothetical cohorts of 100000 girls and 100000 boys originally aged 10-14, as they pass through the various states of the model. In our model, a woman has a life time chance of becoming affected equal to 2.2 percent $(m e n=2.1$ percent). Women develop psoriasis at an average age of 48.7 years (men $=46.8$ years). A woman, who at some time in her life becomes affected, lives on average 30.6 years with the disease. For men, the figure is 27.8 years. Women who are affected have a chance equal to 55.2 percent (men $=52.0$ percent) to be in remission sooner or later.

Since the chances of acquiring psoriasis are low, we only show graphs - see Figure 4 - for the life courses of those of the 100000 boys and girls who have become affected at some point during their life time. Between one-half and two-thirds of the middle-aged in remission live with a partner - at higher ages, union dissolution and death of the partner causes them to live as single. For instance, in the age groups $25-29$ and 50-54, 66.2 percent and 65.8 percent of the women in remission have a 
partner, respectively. However by age 75-79 the share has dropped to 26.1 percent. For men, the shares for these three age groups are 51.7, 64.8, and 37.7 percent, respectively. It is noteworthy to mention that - see again Fig. 4. - with the chosen parameters around 3\% of the individuals appear ever affected in the course of their life and that out of these about one half presents with active disease. These percentages appear in line with current clinical experience.

\section{[Insert Fig $4 a$ and $b$ ]}

We have then simulated the effect of therapy intervention on the marital status of the patients by means of sensitivity analysis, which is merely a technical tool where "arbitrary" changes are made on parameters to assess the effect of the model.

In one model run, we assumed that the chances to be cured would be twice as high as those in the previous analysis (which we will call "benchmark analysis"). In other words, the rate for the transition from PSOSIN to CURSIN (Figure 2) was twice the corresponding value in the benchmark simulations, for both men and women in each age group, and similarly for the transition rate from PSOCPL to CURCPL.

We label this analysis as " $+100 \%$ ". In a second sensitivity analysis we assumed that the transition rates from PSO to CUR would be 50 percent higher, compared to those of the benchmark analysis (" $+50 \% ")$, while a third analysis reflects the assumption of rates that are 50 percent lower ("-50\%"). To check the effects of stronger or weaker success in therapy intervention, we focus on persons who were ever affected, and their chances to live with a partner. The results are reported in Table 1.

The results show that - at least in our simplified model - the impact of improved therapy on the chances for living with a partner, rather than living as single, is extremely limited. Compared to the Benchmark results, the probabilities in Table 1 change by less than two percentage points, often much less. In many cases, improved therapy seems to lead to slightly lower chances to live with a partner. This is likely a composition effect. Since the sensitivity is so low, we have not explored this issue further.

Any effects of improved therapy on the chances for living with a partner are indirect effects. We have assumed that patients who live with a partner have higher rates of "getting cured" compared with those who live without a partner; see Figure 3. The direct effects are much stronger: in a trial calculation (results not shown here) we found that increasing the union dissolution rates for patients who live in a couple quickly results in much lower shares who live with a partner, both at ages 25-29, 50-54, and 75-79, for men and women alike.

\section{Conclusion and Discussion}

The present study represents a first attempt to show, as a matter of principle, the feasibility of applying mathematical modelling in life course to a chronic disease exerting a heavy biopsychosocial impact. There are many limitations to this study: structural limitations of the macro-model do not allow implementing into the model what is presumably a salient aspect of the way the many psychosocial impairments and the multiple comorbidities linked to this diseases end up by substantially "damaging" the patients' life courses: all comorbidities and social disadvantages interact by mutually enhancing each other, so that the effect of the whole group of accompanying conditions is likely to be much more than the sum of the single elements. A further important limitation is that the estimates of transition probabilities are essentially based on clinical experience of the authors only - respectively on the outcome of mostly small surveys; in this sense it is reassuring to see that the obtained percentages of affected individuals at all ages are also in line with clinical experience. 
The present study demonstrates, in principle, the feasibility of an approach based on mathematical models of life course to obtain information on the interaction between a psychosocial and a biological variable, but that macro models may reflect only a part of a complex reality. More sophisticated techniques and different software is needed to represent more realistic situations and to find applications in clinical reality: micro-simulation models, i.e. models describing the life trajectories of single individuals (as well as combined micro-macro models) may turn out to be the proper instruments for future research in this field.

\section{Statement of Ethics}

Not applicable (computer simulation based on clinical experience and epidemiological data)

\section{Disclosure Statement}

The authors have no vested interest to disclose

\section{Acknowledgements}

The authors would like to thank Åke Svensson (Malmö), Jon-Anders Halvorsen (Oslo) and Olga Zenkevich (Padua) for their suggestions.

\section{Bibliography}

1. Linder MD, Piaserico S, Augustin M et al. Psoriasis - The Life Course Approach. Acta Derm Venereol. 2016 Aug 23; 96(217): 102-8.

2. Hong J, Koo B, Koo J. The psychosocial and occupational impact of chronic skin disease. Dermatol Ther. 2008 Jan-Feb; 21(1): 54-9.

3. Daudén E, Castañeda S, Suárez C et al Clinical practice guideline for an integrated approach to comorbidity in patients with psoriasis. J Eur Acad Dermatol Venereol. 2013 Nov;27(11):1387-404.

4. Azfar RS, Gelfand JM. Psoriasis and metabolic disease: epidemiology and pathophysiology. Curr Opin Rheumatol. 2008 Jul; 20(4): 416-22.

5. Connor CJ, Liu V, Fiedorowicz JG. Exploring the Physiological Link between Psoriasis and Mood Disorders. Dermatol Res Pract. 2015; 2015: 409637.

6. Dowlatshahi EA, Wakkee M, Arends LR, Nijsten T. The prevalence and odds of depressive symptoms and clinical depression in psoriasis patients: a systematic review and meta-analysis. J Invest Dermatol. 2014 Jun; 134(6): 1542-51.

7. Kimball AB, Gieler U, Linder D et al. Psoriasis: is the impairment to a patient's life cumulative? J Eur Acad Dermatol Venereol. 2010 Sep; 24(9): 989-1004.

8. Bask M, Bask M. Cumulative (Dis)Advantage and the Matthew Effect in Life-Course Analysis. PLoS One. 2015 Nov 25; 10(11): e0142447. doi: 10.1371/journal.pone.0142447.

This article is protected by copyright. All rights reserved. 
9. http://biblehub.com/matthew/25-29.htm last access July $26^{\text {th }}, 2017$.

10. Sampogna F. Setting up a life course questionnaire. Curr Probl Dermatol. 2013; 44: 67-73.

11. Barban N, Linder M D, Mathematical Modelling in Life Course Research. Curr Probl Dermatol. 2013; 44:33-46. doi: 10.1159/000350747.

12. Saltelli A, Tarantola S, Campolongo F, Ratto M, Sensitivity Analysis in Practice, J Wiley \& Sons, 2004.

13. http://www.nidi.knaw.nl/en/research/al/270101, last access July $26^{\text {th }}, 2017$

14. Van Imhoff (E.) Keilman (NW) - LIPRO 2.0: an application of a dynamic demographic projection model to household structure in the Netherlands, Amsterdam: Swets and Zeitlinger 1991

15. Burden-Teh E, Thomas KS, Ratib S, Grindlay D, Adaji E, Murphy R. The epidemiology of childhood psoriasis: a scoping review. Br J Dermatol. 2016 Jun; 174(6): 1242-57.

16. Alho J, Keilman N. On future household structure. Journal of the Royal Statistical Society Series A 173(1) 2010: 117-143.

17. Goldman, N. (2015). Mortality differentials: Selection and causation. In J. Wright (Ed.), International Encyclopedia of the Social and Behavioral Sciences, 2nd edition, Vol 15 (pp. 851-856). Elsevier.

18. Helmick CG, Lee-Han H, Hirsch SC et al. Prevalence of psoriasis among adults in the U.S.: 2003-2006 and 2009-2010 National Health and Nutrition Examination Surveys. Am J Prev Med. 2014 Jul; 47(1):3745 .

19. Rachakonda TD, Schupp CW, Armstrong AW. Psoriasis prevalence among adults in the United States. J Am Acad Dermatol. 2014 Mar; 70(3):512-6.

20. Parisi R, Symmons DP, Griffiths CE et al.; Identification and Management of Psoriasis and Associated Comorbidities (IMPACT) project team. Global epidemiology of psoriasis: a systematic review of incidence and prevalence. J Invest Dermatol. 2013 Feb; 133(2): 377-85.

21. Jankovic S, Raznatovic M, Marinkovic J et al. Risk factors for psoriasis: A case-control study. J Dermatol. 2009 Jun; 36(6): 328-34.

22. Gelfand JM, Troxel AB, Lewis JD et al. The risk of mortality in patients with psoriasis: results from a population-based study. Arch Dermatol. 2007 Dec; 143(12): 1493-9.]

23. Keyfitz N, Caswell H, Applied Mathematical Demography, $3^{\text {rd }}$ ed. 2005, NewYork: Springer.

24. Frangos JA, Kimball AB, Divorce/marriage ratio in patients with psoriasis compared to patients with other chronic medical conditions. J Invest Dermatol 2008; 128(Suppl 1):S87.

25. Jin J, Sklar GE, Min Sen Oh V, Chuen Li S. Factors affecting therapeutic compliance: A review from the patient's perspective. Ther Clin Risk Manag. 2008Feb;4(1):269-86. PubMed PMID: 18728716; PubMed Central PMCID: PMC2503662

This article is protected by copyright. All rights reserved. 


\begin{tabular}{|c|c|c|c|c|}
\hline & $-50 \%$ & Benchmark & $+50 \%$ & $+100 \%$ \\
\hline Age group & \multicolumn{4}{|c|}{ Women } \\
\hline $25-29$ & 57.4 & 57.5 & 57.7 & 57.9 \\
\hline $50-54$ & 61.8 & 61.7 & 61.7 & 61.8 \\
\hline $75-79$ & 25.6 & 24.3 & 23.7 & 23.3 \\
\hline & \multicolumn{4}{|c|}{ Men } \\
\hline & 42.5 & 42.7 & 42.8 \\
\hline $25-29$ & 42.5 & 57.0 & 57.1 & 57.2 \\
\hline $50-54$ & 57.0 & 33.8 & 33.0 & 32.6 \\
\hline $75-79$ & 35.3 &
\end{tabular}

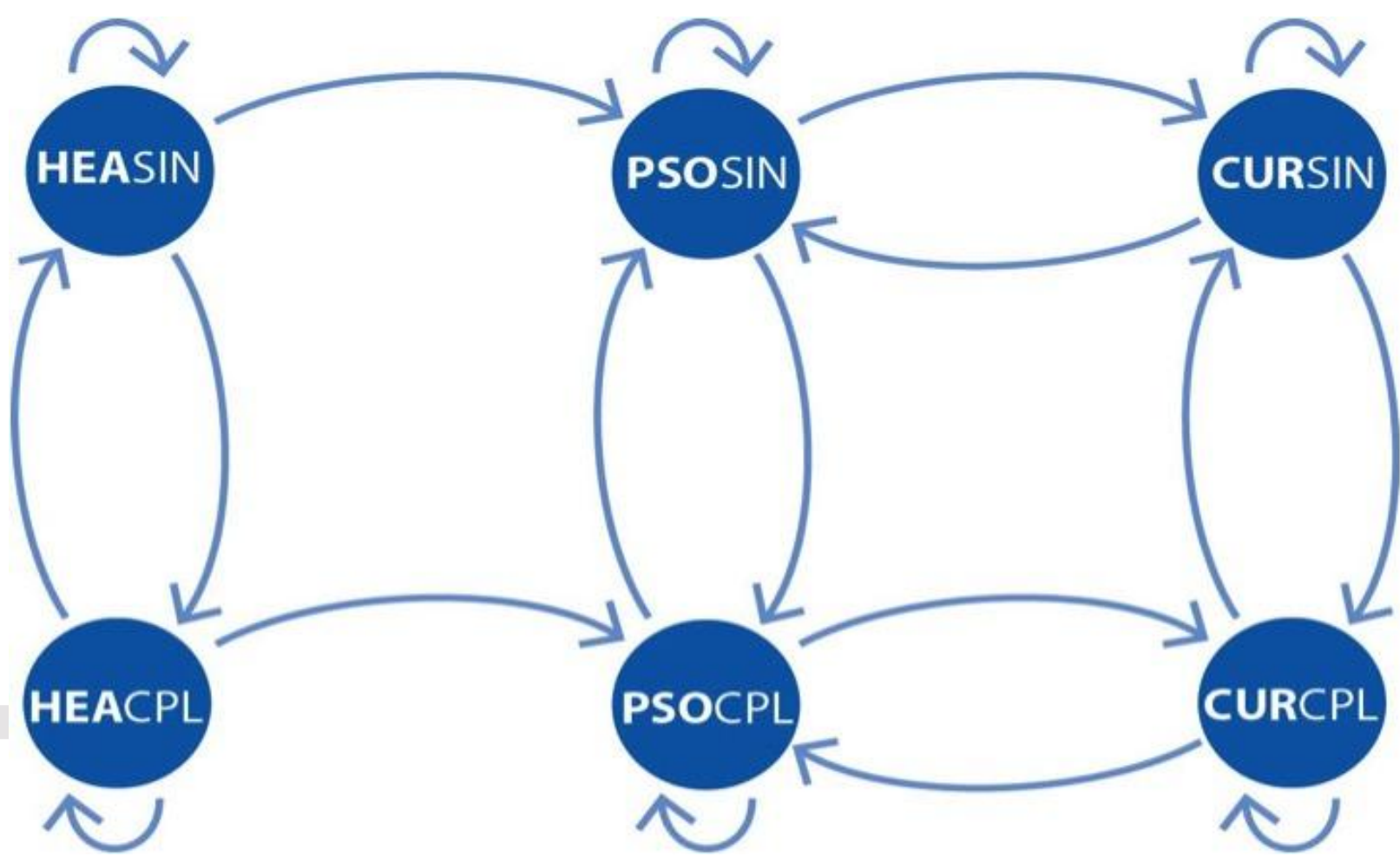

This article is protected by copyright. All rights reserved. 

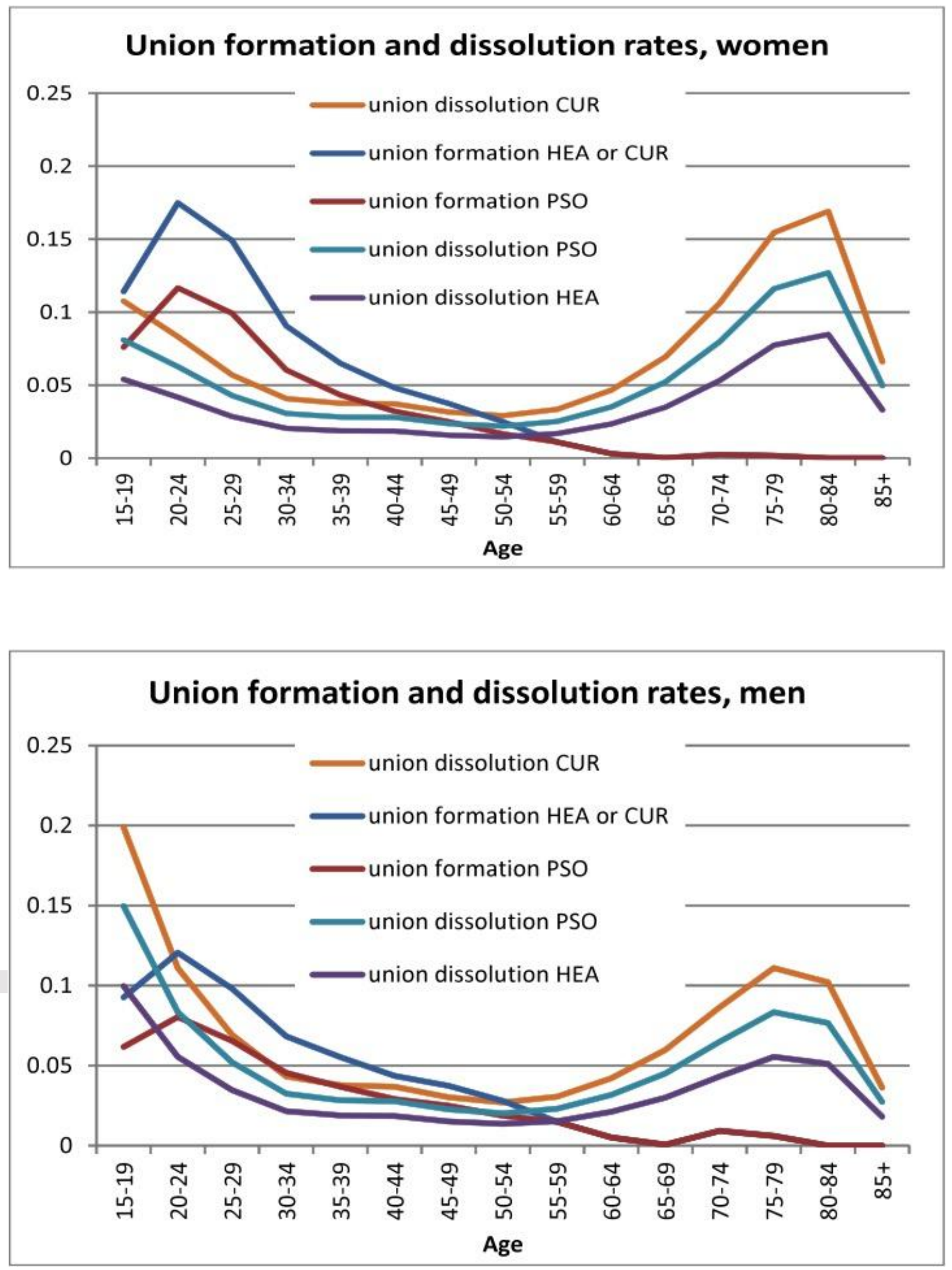

This article is protected by copyright. All rights reserved. 

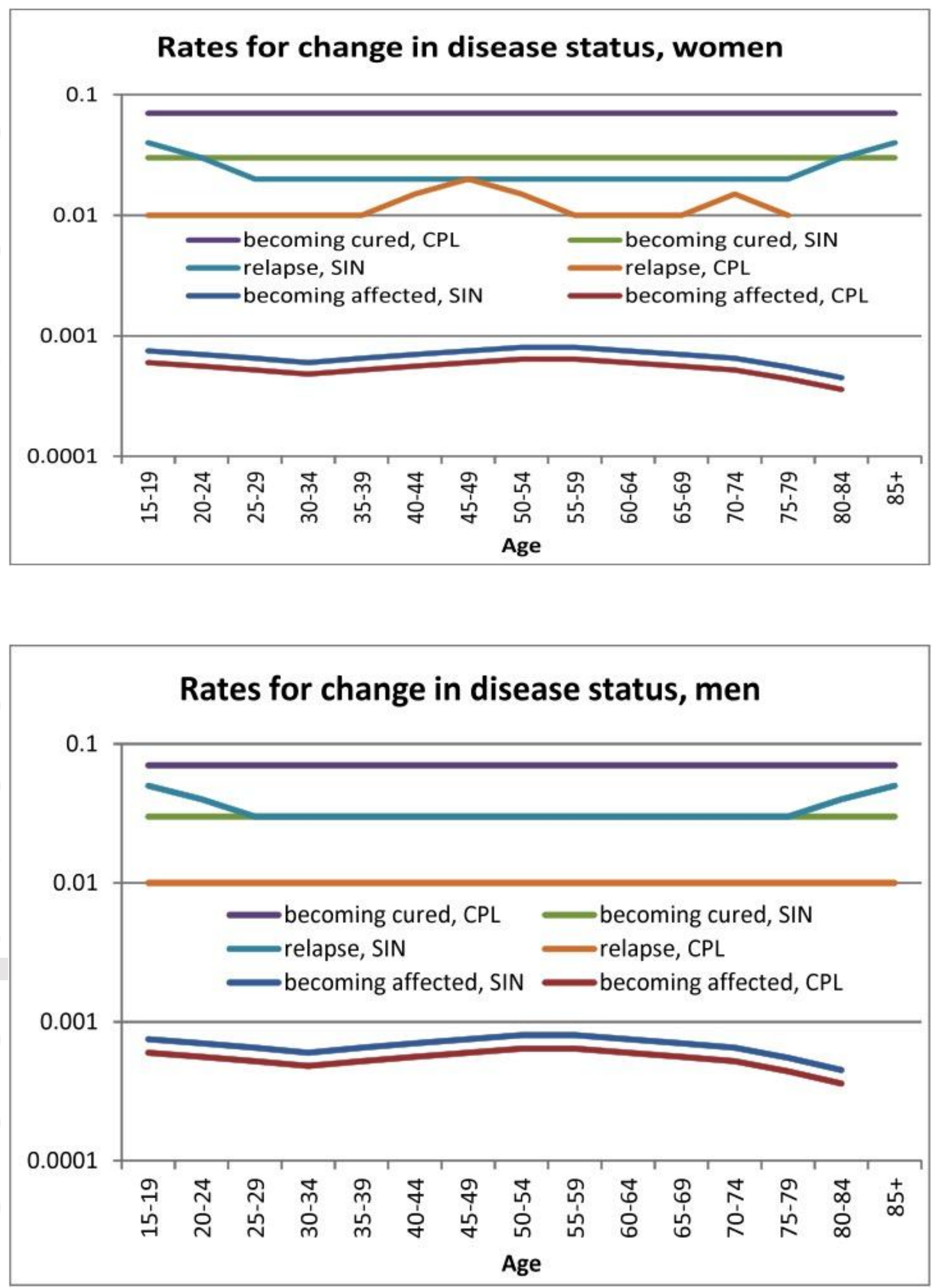

This article is protected by copyright. All rights reserved. 


\section{Life table results, women who became affected}

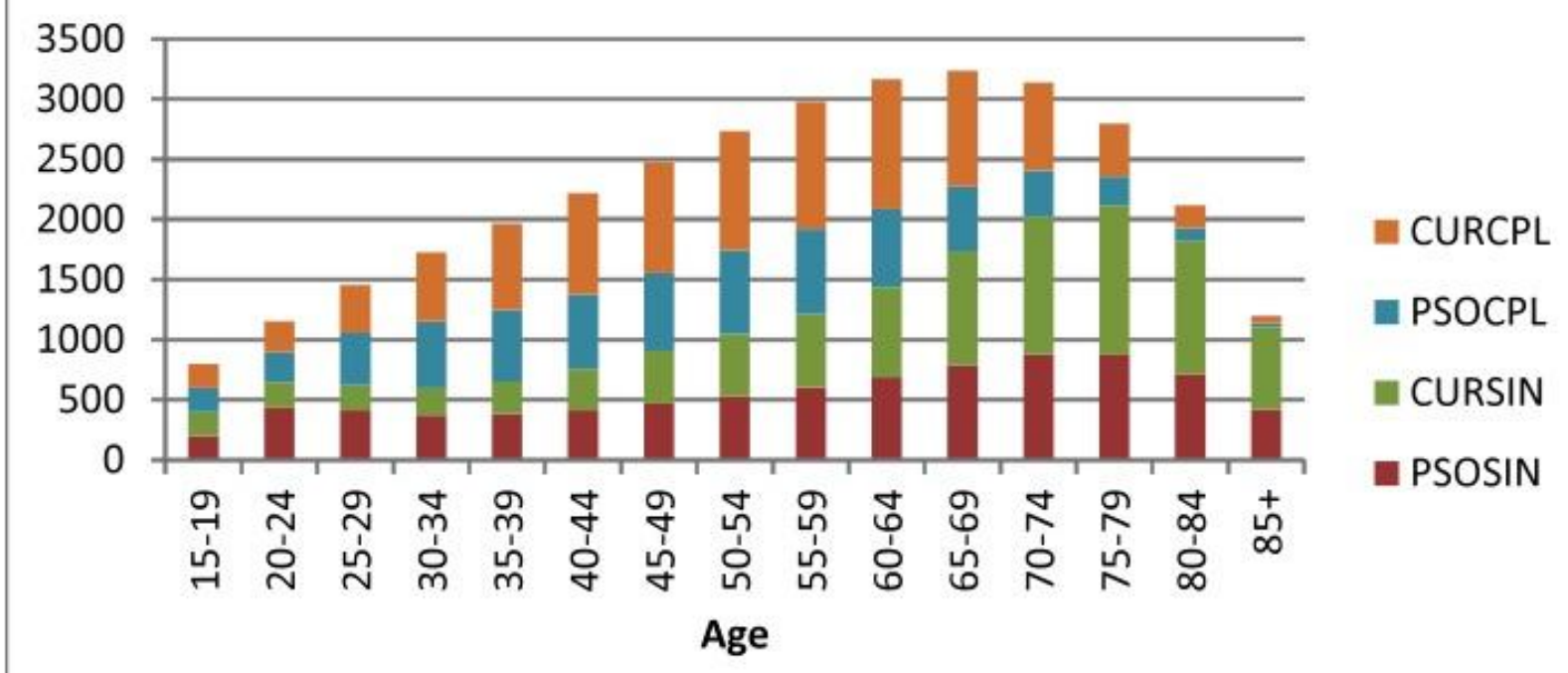

\section{Life table results, men who became affected}

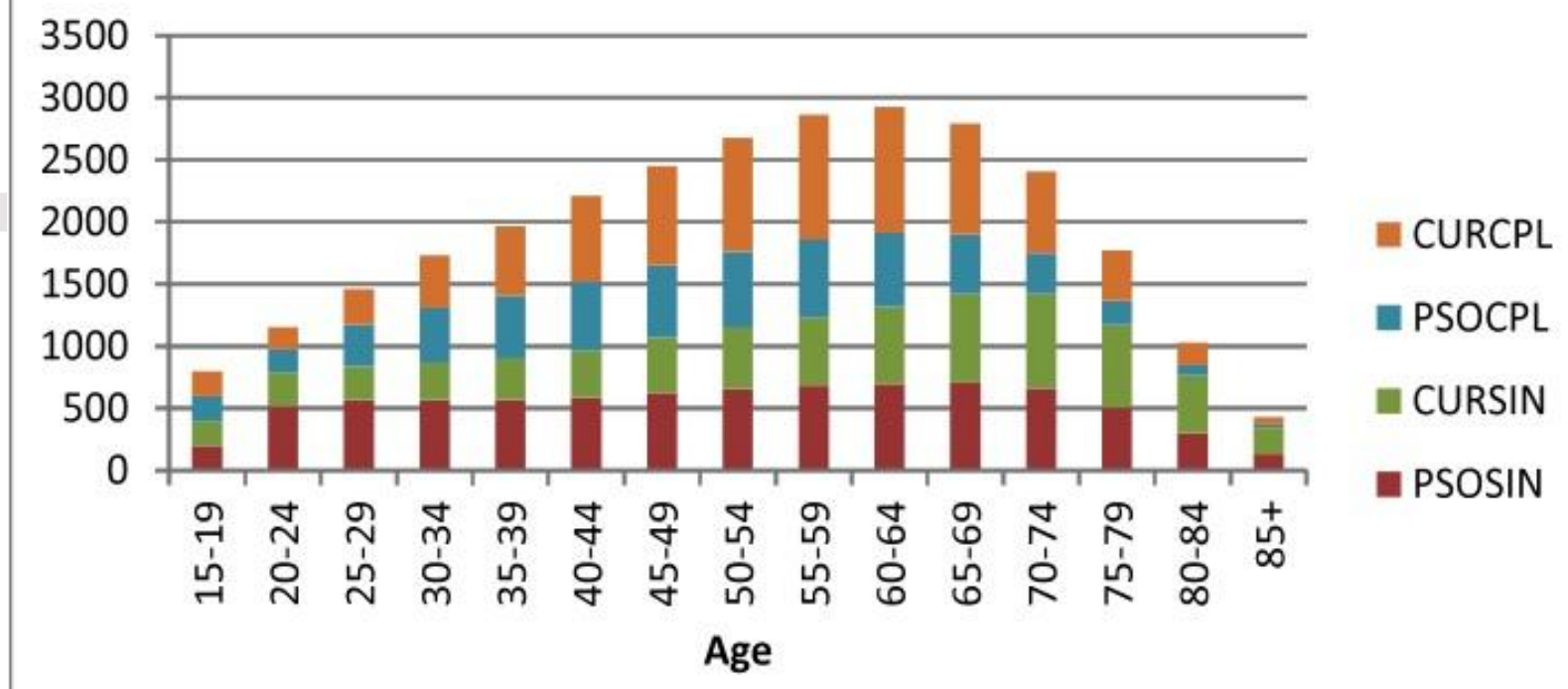

